\title{
The Role of Public Media in Education and Publicity in the Hundred Days' Reform
}

\author{
Fan Cuihong \\ School of Marxism \\ Jinan university \\ Jinan Shandong, P.R.China \\ sss_fanch@ujn.edu.cn
}

\begin{abstract}
During the Hundred Days' Reform Movement period, with the rapid change of society and increasingly serious national crisis, newspaper, periodicals and society are emerging widely which has a profound impact on the social life of that period and has also become tools and practical means of the Hundred Day's Reform. Its emergence has played unusual role in many aspects such as the guidance of public opinion, public participation and social integration.
\end{abstract}

Keywords—newspaper;society;public media;education and publicity functions

\section{INTRODUCTION}

The years between Sino-Japanese War and the Hundred Days' Reform is an important historical period as a turn in the history of modern China. In the Sino-Japanese War, we lost miserably to a Japanese pirates from such a small country that we looked down upon and even had to cede the territory of the land of dragon arising of Qing Dynasty. This burning shame had stimulated the people of various circles, noble-minded patriot to fill with indignation and the national recognition had to change earnestly and the national awakening of group signification began from here. The unprecedented severe national crisis and rapid deterioration of the living situation calls for increasingly reform all over the country. Chinese began to strive for a way out through institutional innovation and China politics has entered into a historical phase of large-scale change. Going with this stream, various kinds of constitutional reform newspapers and periodicals turned up like bees rising in swarms, various kinds of societies established one after another. Newspapers, periodicals and societies played the roles of public media, born the detailed and complicated social and political functions such as guidance of public opinion, public participation and social integration and has also become the tools and practical means for Hundred Days' Reform.

\section{GREAT EMERGING OF NEWSPAPER AND PERIODICALS}

Newspaper and periodical is an important mass media coming along with the development of society economy and culture. The rise of modern Chinese newspapers and periodicals stems from the Westerners after the Opium war. With the invasion of foreign capitalism and the eastward transmission of western sciences, some foreign missionaries and businessmen established some newspapers and periodicals in china. According to the Statistics, within nearly half century between 1940s to 1990s, foreign businessmen and missionaries have set up nearly 170 kinds of Chinese and foreign newspapers, accounting for about $95 \%$ of the total number of newspapers and periodicals in the same period [1]. Among them, greater influential Chinese newspaper and periodicals such as "The Review of the Times", "Shun Pao","Times"etc. greater influential foreign newspaper and periodicals such as "North China Herald","North China Daily News",etc. But generally speaking, the newspaper and periodicals before the SinoJapanese War had limited impact from the angle of social transformation and political change due to the fact that they were established by foreign businessmen and missionaries, the content of which is mainly religious preaching, business information, and missionary activities.

After the defeat of the Sino Japanese War, dramatic changes in the situation at home and abroad ideas of saving the nation from subjugation and reforming spread quickly in public. Bourgeois reformers came upon the political stage under this opportunity. The advocated the idea of reform and then guided the new trend of reform into The Hundred Days' Reform of which the core is political reform. The enthusiasm for starting newspapers of Chinese people quickly rose and many newspapers spring up like mushrooms. Among them, more famous and influential newspapers are:"Domestic and Foreign News","Qiang Xue Bao" "Newspaper of Current Affairs",“Guo Wen Daily”,"The Reformer China”, "Journal of Hunan"and"Xiang Newspaper” etc. These journals and periodicals are the position and platform for the reformers to publicize their political views and introduce western knowledge.

Similar with the springing up of the newspapers and periodicals, another phenomenon in the period of reform is the society of reform rising up and blossoming in radiant splendor. After the Sino-Japanese War, the national survival crisis emerges and the danger of national subjugation and genocide highlighted. Under this background, the society emerges as the times require and has become an important of practical means of the reformers. In August 1895, Kang Youwei and Liang Qichao, Wen Tingshi, Shen Cengzhi founded Society for Strengthening China in Beijing, which is the first during the reform movement. In October 1895, 
Kang Youwei and Zhang Zhidong founded the Society for Strengthening China in Shanghai. Talents of various industries come together. Establishing Societies here got response from all over the country. Under the example of Kang Youwei and Liang Qichao of the Society for Strengthening China, the tide for establishing society during the period of reform sprung up quickly. The record of society which can be traced is in total 72 and spread 30 countries all over the country.

\section{The Guidance OF PUBLIC OPINION}

After the Sino- Japanese War, the newspapers and periodicals and societies developed rapidly and they played institutionalized role of public media in the national crisis and they become tools and practical means for promoting the reform. This kind of public media is not only the material carrier of information communication and the intermediary and link to connect people from all walks of life, but also the tools for formation, copy, spreading and zooming of society public opinion. They concentrate the thought of reform of the elite and advocate the effect and influence so that more and more public can focus on this point and also to create public topic and then to create a new thought and public opinion atmosphere in the whole society. The most representative ones are "The Chinese Progress", "GuoWen Daily", Society for Strengthening China and Society for Protection of China.

Liang Qichao as the editor in Chief spread his own thought to the society and agitated and influence the public opinion. His" reform through discussion in the "current affairs" on the series 21 , a comprehensive theory of politics and economy and cultu re, education, military and other aspects of the reform, is regarded as a programmatic document of the reformers, caused widespread repercussions in society. After half a year from the initial publication of each 4000 copies to 7000 copies, a year later, it reached 13000, the highest exceeded 17000 copies[2]. It issued 15 provinces throughout the country and Southeast Asia and Japan Overseas Chinese community [3]. This is enough to see the inspiration of public media.

The function of Society in encouraging the reform of public opinion, dissemination of new knowledge, and the role it played in opening of the atmosphere should not be underestimated. During the period of the reform, there are some professional academic groups, but most of them are engaged in social activities such as politics, economy, culture, education. The society shall be incorporated into the track of the reform movement with the aim from the perspective of political and social change. Society created public opinion, expanded the momentum, connect the talent, and made the cohesion, so that everyone concerned about the fate of the country, and then to promote the political reform.

\section{POLITICAL PARTICIPATION}

The flourishing of the Hundred Days' Movement of newspapers and periodicals to contact the feelings between literati, communicate, discuss the problem and provided an open platform for communication and planning activities, improvement of social reform.A large number of intellectuals were gathered and contacted by the public media of which the newspaper and periodicals and Society were the center. In the "current affairs" as an example, the writer such as Liang Qichao, Wang Kangnian, $\mathrm{Xu}$ Qin, Mai Menghua, Zhang Taiyan, Zheng Xiaoxu and other elites from the field are gathered in Shanghai, advocated and propaganda reform. In this group of knowledge driven by the elite, the public deeply involved in the free discussion. Just as some scholars said: "these newspapers, as the most important public space, on the one hand, it aggregated the intellectual groups, and on the other hand, they provided the necessary materialized conditions for the realization of value. Intellectuals are often achieved their duty by their participation in social affairs, establishment of public values through speaking out to the society. Newspapers as the social media, not only stimulate their thinking function, but also provides for the expression of their ideological positions" [4].The issuance of newspaper and periodicals and the reading of periodicals between social elite and the public build platform for exchanging ideas. It is estimated that the direct readers of "Newspaper of Current Affairs" are about 200,000people, and the indirect audience is about 1 million people[5]. The wide range of the audience, is not only officials, businessmen, but also the general public in the lower middle class; not only the old literati, but also the intellectuals and young students in the new world.

The role of society is more direct in cultivating and connecting the talents and organizing social forces to participate in political activities. It is considered that the formation of society is an important way to cultivate talents and organize the team. Society is the communication link and the talent aggregation and interdependent in the hundred days' reform.

\section{THE FunCTION OF SOCIAL INTEGRATION}

In general, the orderly running of any society cannot be separated from the necessary integration mechanism. The so-called integration refers to that a number of elements modified and stuck together into a more or less same model of thinking and action, and a relatively complete system of collaborative functions. In accordance with the different of integration of power, different of integration of means, the different integration of goals, it can be divided into two categories: first, the political state or government as the core of political integration; first, the unofficial civil society as the core of social integration. The integration of public media naturally belongs to social integration, it is through newspapers periodicals, and civil institutions as the intermediary, by way of non-administrative integration, coordinate the various relations, so as to realize effective social mobilization, to create a good atmosphere of social and cultural psychology, and guide people to strive for a common goal.

After the Sino-Japanese War, in the face of increasingly serious internal and external crises, there are various comments or suggestions between government officials and non-officials, businessman and scholars and either in the form of memorial to the throne or in the form of written comments, comments or ideas. Different people, different views, but in the standpoint and the 
specific content and showing the chaos miscellaneous weeds, even contradictory situation. Fundamentally, these beings noisy arguments and propositions only reflect the different individuals or different social classes of views and opinions. In the guidance of the reformists, through the integration of newspapers and magazines the discussion focused more and more in-depth, and theme the more distinctive, and reach a consensus on some basic issues, such as the idea of political reform, the right to set the house on public advocate, on the abolition of the imperial examination, starting school. All these above propositions have been widely recognized, and the ideology has been united in the society level.

From the organizational level perspective, during the Hundred Days' Reform, all kinds of society, newspaper polymerization is often a group of like-minded people, their common values or political beliefs based on and together in one place, they seek public interest groups and even the whole society as the goal, and actively transmission of western new knowledge, or pay attention to civilized customs, or attention in industry, or engaged in various activities of social change. The existence of this kind of society and newspaper polymerization is not only to strengthen mutual relations and solidarity among the people of all ranks, provides a wide range of channels and a wide space to express their interest demands, but also provide the necessary practice opportunities and means for them to participate in social and national affairs, but also help to improve their group and the sense of identity and sense of belonging.

In short, under the historical background after the Sino-Japanese war that the national crisis is becoming more and more serious, as public media, newspapers and society plays an extraordinary social and political function both in public opinion and political participation as well as in social integration.

\section{REFERENCES}

[1] Fang Hanqi. modern history of china's newspapers and magazines [M].Taiyuan: Shanxi People's Publishing House,1981.p18.

[2] Fang Hanqi. modern history of china's newspapers and magazines [M].Taiyuan: Shanxi People's Publishing House,1981.p83.

[3] (America)John K. Fairbank,Liu Guangqing. Late Cambridge Chinese History of Qing Dynasty (volum II) [M].Beijing:China Social Sciences Publishing House, 1985.p387.

[4] Ding Xiaoyuan. New public space and the late qing dynasty prose style [J].Academic Research,2005,(2).

[5] Lui Xiaopo. Media in China's early modernization [M].Shanghai:San Lian Book Store,1995.p180. 